\title{
Hepatitis delta
}

INSERM

\section{Source}

INSERM. (1999). Orphanet: an online rare disease and orphan drug data base. Hepatitis delta. ORPHA:402823

Hepatitis delta is a rare hepatic disease characterized by variable degrees of acute hepatitis resulting from infection with the hepatitis delta virus. Occasionally it may present a benign course, but most frequently it manifests with severe liver disease that may include fulminant liver failure, hepatic decompensation and rapid progression to cirrhosis. All patients present concomitant hepatitis B virus infection and an increased risk of developing hepatocellular carcinoma has been reported. 